\title{
Apontamentos para pensaro ensino de História hoje: reformas curriculares, Ensino Médio e formação do professor ${ }^{*}$
} Marcelo de Souza Magalhães**

O artigo situa os Parâmetros Curriculares Nacionais (PCN) para o Ensino Médio em meio a um conjunto de políticas públicas de educação implementadas nos anos 1990. Em seguida, recupera aspectos da história do Ensino Médio, para entender o projeto de reforma deste nível contido nos PCNs. Por fim, aponta alguns limites desta proposta, a partir de uma reflexão sobre o ensino da História e a formação do professor. Palavras-chave: Ensino Médio - Ensino de História - Formação de professores

Notes on the teaching of History in Brazil today: curriculum reformation, high education and teachers' formation

The present article focuses the "National Guidelines for High Education" (PCN - Parâmetros Curriculares Nacionais) issued by the brazilian government as part of its educational agenda during the 90's. The author firstly analyses the history of high education in Brazil, aiming to understand the reformation proposed by the government, and secondly, he discusses its limitations in regard to the History teaching and to the teachers' formation.

Keywords: High education - History teaching - Teacher's formation

\footnotetext{
"Artigo recebido em abril de 2006 e aprovado para publicação em junho de 2006.

** Professor do Departamento de Ciências Humanas da UERJ e doutor em História Social pela UFF. E-mail: marcelosmagalhaes@hotmail.com.
} 
Notes pour réfléchir sur l'enseignement d'histoire aujourd'hui : réformes des programmes, enseignement dans les lycées et formation des enseignants Cet article cherche à placer les Paramètres des Programmes Nationaux pour l'enseignement au niveau des lycées dans le contexte des politiques publiques d'éducation établies dans les années 90. On reprend aussi certains aspects de l'histoire de l'enseignement dans les lycées afin de comprendre le projet de réforme de ce niveau d'enseignement compris dans les Paramètres des Programmes Nationaux. Finalement, on montre quelques limites de cette proposition à partir d'une réflexion sur l'enseignement de l'histoire et sur la formation des enseignants.

Mots-clefs: Lycées - Enseignement de l'histoire -Formation des enseignants

As décadas de 1980 e 1990 foram marcadas por reformulações curriculares no Brasil, promovidas por estados e municípios, que não necessariamente surtiram efeito na modificação de práticas docentes. Estas reformulações têm relação direta com a transição da ditadura civil-militar para um período democrático, em um mundo em processo de globalização.

Após 1982, os governos estaduais eleitos rediscutiram o que se ensinava nas escolas, em meio a uma reação dos educadores brasileiros contra os currículos mínimos estabelecidos a partir da Lei de Diretrizes e Bases (LDB) da Educação de 1971 (nº 5.692, de 11/08/71). ${ }^{1}$

A LDB reforçava a tradição herdada dos anos 1930, de centralização das tomadas de decisão sobre a escola. Atribuía aos Conselhos Federal e Estadual de Educação as definições do núcleo comum de conteúdos e da parte diversificada do ensino, respectivamente. Em tese, o planejamento era feito fora da escola, por órgãos de governo criados para tal fim. Isto provocou a resistência dos professores às propostas curriculares, quase sempre vistas como "pacotes" externos, distantes da realidade escolar. ${ }^{2}$

As reformulações curriculares dos anos 1980 e 1990 tentaram romper com a idéia de impor um "pacote" diretivo à escola. Em função disto, as Secretarias de Educação procuraram construir suas propostas pela via do diálogo com os

${ }^{1}$ Sobre as reformas curriculares após a ditadura militar, cf. Selva Guimarães Fonseca, Caminhos da história ensinada, Campinas, Papirus, 1995.

${ }^{2}$ Ibidem, p. 53-54. 
Apontamentos para pensar o ensino de História hoje: reformas curriculares, Ensino Médio e formação do professor

professores das redes, através de reuniões e de escolhas de representantes docentes. Esta mudança foi significativa, já que o professor, em alguns casos, deixou de ser entendido apenas como transmissor de conhecimento e passou a desempenhar o papel de co-autor, apesar da impossibilidade de mobilizar todos os docentes.

Em meados da década de 1990, este movimento de reformulação curricular trilhou um novo rumo. Pela primeira vez após a ditadura, a União tomou para si a responsabilidade de rever os currículos existentes, estabelecendo parâmetros básicos. As propostas então desenvolvidas sofreram inúmeras críticas, sendo algumas rejeitadas pelos docentes, como foi o caso dos Parâmetros Curriculares Nacionais (PCNs) para o Ensino Médio.

Divulgados em 1999, os PCNs buscavam superar a lógica disciplinar presente nas escolas. ${ }^{3}$ Entre outras coisas, propunham reorganizar o Ensino Médio em três áreas: Linguagens, códigos e suas tecnologias, Ciências da Natureza, Matemática e suas tecnologias e Ciências Humanas e suas tecnologias. No último ano de governo de Fernando Henrique Cardoso, foram publicados os PCNs, contendo um volume para cada área de conhecimento. ${ }^{4}$ Esta versão mais detalhada das áreas surgiu como resposta às críticas feitas ao primeiro documento, havendo um significativo investimento no sentido de convencer o professor da qualidade da proposta e da vantagem em adotá-la. Em 2004, agora sob o governo de Luis Inácio Lula da Silva, voltou-se a discutir estes PCNs. Depois de idas e vindas, o MEC finalmente reconheceu a pouquíssima recepção que a proposta teve entre os professores do Ensino Médio. ${ }^{5}$ A retomada da discussão se deu a partir da divulgação de documentos preliminares, escritos por especialistas, acerca do papel de cada disciplina no interior das áreas de conhecimento. ${ }^{6} \mathrm{~A}$ fim de compreender sua restrita recepção, tendo como foco o ensino escolar da História, propõe-se realizar três movimentos:

\footnotetext{
${ }^{3}$ BRASIL, SEGRETARIA DE EDUCAÇÃO MÉDIA E TEGNOLÓGICA, Parâmetros curriculares nacionais, ensino médio, volume 1 - Bases legais, e volume 4 - Ciências Humanas e suas tecnologias, Brasília, MEC/SEMTEC, 1999.

${ }^{4}$ Idem, PCN+ Ensino Médio: orientações educacionais complementares aos Parâmetros Curriculares Nacionais: ciências humanas e suas tecnologias, Brasília, MEC/SEMTEC, 2002.

${ }^{5}$ BRASIL, SECRETARIA DE EDUCAÇÃO BÁSICA, Orientações curriculares do Ensino Médio, Brasília, Ministério da Educação, 2004 (http://portal.mec.gov.br/seb/arquivos/pdf/ 01Apresentacao.pdf).

${ }^{6}$ Holiem Gonçalves Bezerra, "Ciências Humanas e suas tecnologias - História”, ibidem, p. 278-313 (http://portal.mec.gov.br/seb/arquivos/pdf/11Historia.pdf).
} 
1. situar os PCNs em meio a um conjunto de políticas públicas de educação, implementadas a partir de meados dos anos 1990; 2. recuperar aspectos da história do Ensino Médio, para compreender o projeto de reforma deste nível contido nos PGNs; 3. apontar alguns limites desta proposta, a partir de uma reflexão sobre o ensino da História e a formação do professor. ${ }^{7}$

\section{Um ministro e suas políticas para a educação}

Ao ler textos de educadores que analisam as políticas públicas de educação implementadas pelo MEC, durante a gestão de Paulo Renato Souza, ${ }^{8}$ é difícil chegar a qualquer conclusão. Tem-se a impressão de não existir consenso acerca dos benefícios destas políticas. Por vezes, alguns aspectos são elogiados. Outras vezes, todas as ações implementadas são criticadas, sendo acusadas de estarem distantes dos projetos formulados por educadores brasileiros e próximos da agenda para a educação proposta por órgãos internacionais, tais como: a UNESCO, o BID e o BIRD. Os órgãos internacionais são freqüentemente vistos como defensores de interesses externos à sociedade brasileira, muito ligados a grandes corporações transnacionais. ${ }^{9}$ A ausência de um consenso mínimo acerca dos benefícios destas políticas públicas é um sinal do quanto as questões relacionadas à educação eram, na época, como são até hoje, alvos de intensas disputas, em que diversos grupos, com seus projetos políticos, concorrem entre si.

Reconhecendo a complexidade do tema, busca-se aqui apenas situar os PCNs como parte de um conjunto mais largo de ações. Durante a gestão

\footnotetext{
${ }^{7}$ Os PCNs para o Ensino Fundamental não sofreram uma rejeição tão grande dos professores. Porém, tal qual os PCNs para o Ensino Médio, foram relativamente pouco implementados.

${ }^{8}$ Paulo Renato Souza foi ministro da Educação por 8 anos, de 1995 a 2002, ocupando o cargo durante os dois mandatos do presidente Fernando Henrique Cardoso. Sua permanência no cargo só foi inferior à de Gustavo Capanema, que ocupou o ministério por 11 anos, de 1934 a 1945. Antes de ser ministro, passou por duas experiências de gestão na área de educação. Em 1984, foi Secretário de Educação do Estado de São Paulo, no governo de Franco Montoro. Entre 1986 e 1990, foi Reitor da UNICAMP. Ocupou ainda alguns postos em órgãos internacionais. Nos anos 1970, desempenhou as funções de especialista e dirigente regional, no Chile, da Organização Internacional do Trabalho (OIT), da Organização das Nações Unidas (ONU). Na primeira metade dos anos 1990, foi gerente de operações e vice-presidente executivo do Banco Interamericano de Desenvolvimento (BID).

${ }^{9}$ Para as críticas às políticas públicas de educação no Brasil, em sua relação com instituições estrangeiras, cf. Gaudêncio Frigotto e Maria Ciavatta,"Educação Básica no Brasil na década de 1990: subordinação ativa e consentida à lógica do mercado", Educação \& Sociedade, Vol. 24, n- $82,2003$.
} 
Apontamentos para pensar o ensino de História hoje: reformas curriculares, Ensino Médio e formação do professor

do ministro, pode-se claramente perceber uma marca. O MEC, em conjunto com o Conselho Nacional de Educação (CNE), se dedicou muito à tarefa de planejamento educacional, através de uma intensa produção de propostas curriculares, então denominadas de diretrizes..$^{10}$

Em dois anos, 1998 e 1999, a Câmara de Educação Básica (CEB) emitiu pareceres e aprovou resoluções sobre as diretrizes curriculares nacionais para a Educação Infantil, o Ensino Fundamental, o Ensino Médio, a Educação Profissional de Nível Técnico e a Formação de Docentes, em nível médio, na modalidade Normal. Por sua vez, nos anos 2000, a Câmara de Ensino Superior (CES) desempenhou papel importante na aprovação de resoluções acerca das diretrizes curriculares nacionais dos cursos de graduação. ${ }^{11}$

Os PCNs para os ensinos Fundamental e Médio fazem parte deste esforço de planejamento do MEC, tendo, certamente, relação direta com o fim da ditadura civil-militar e, além disto, com a LDB de 1996, que atribuiu à União o papel de formular diretrizes para o Ensino Superior e para a Educação Básica, em conjunto com os estados e os municípios.

As diretrizes curriculares, bem como os PCNs para o Ensino Médio, possuem uma característica comum: foram organizados a partir da definição de competências e habilidades a serem desenvolvidas pelos alunos ao longo do processo de ensino-aprendizagem. Logo, tanto para as diretrizes curriculares como para os PCNs, mais importante do que aprender um conteúdo relativo a uma área de conhecimento é desenvolver procedimentos que permitam ao aluno aprender a conhecer. Grande parte das diretrizes não faz qualquer menção aos conteúdos a serem trabalhados, listando apenas as tais competências e as habilidades. Esta forma de organizar os currículos, presente em outros países, tornou-se hegemônica na produção legal do governo brasileiro desde o final dos anos 1990.

O importante a ressaltar é que não há consenso entre os educadores brasileiros no que diz respeito à organização de currículos a partir de competências e habilidades. Há fortes dúvidas acerca de como, consensualmente, defini-las em áreas menos procedimentais, como é o caso de História. Em disciplinas como Português e Matemática, é mais fácil chegar a um consenso sobre as competências e as habilidades. Em Matemática, por exemplo, ao

\footnotetext{
${ }^{10} \mathrm{O}$ CNE é composto pela Câmara de Educação Básica e pela Câmara de Ensino Superior. ${ }^{11}$ As diretrizes curriculares para os cursos de História foram estabelecidas pela Resolução CNE/CES n n- 13, de 13 de março de 2002.
} 
final de um certo tempo de estudo, é possível avaliar se o aluno será capaz de realizar as quatro operações: adição, subtração, multiplicação e divisão. Criticando a estruturação dos currículos a partir de competências e habilidades, pesquisadores alertam que tais termos estão comprometidos com um certo aprender a fazer, muito relacionado ao mundo da produção.

Além do planejamento, houve um investimento significativo do MEC na construção de instrumentos de avaliação capazes de realizar um diagnóstico qualitativo do sistema educacional brasileiro. Tarefa que também foi definida como uma atribuição da União na LDB de 1996. Porém, neste caso, a montagem de instrumentos de avaliação é anterior e decorre de pressões externas, feitas por órgãos internacionais, como a UNESCO. Na gestão de Paulo Renato Souza, o Sistema de Avaliação da Educação Básica (SAEB) foi aperfeiçoado e outras avaliações foram criadas: o Exame Nacional do Ensino Médio (ENEM) e o Exame Nacional de Cursos (ENC), todos sob a responsabilidade do INEP.

$\mathrm{O} \mathrm{SAEB}^{12}$ e o ENEM ${ }^{13}$ da mesma forma que as diretrizes curriculares e os PCNs para o Ensino Médio, são organizados com vistas a aferir se os alunos desenvolveram, ou não, as competências e as habilidades de cada nível de ensino. ${ }^{14}$ Estes instrumentos de avaliação, produtores de uma série de

\footnotetext{
${ }^{12}$ O Sistema de Avaliação da Educação Básica foi criado pelo governo da União em 1988. Consiste na coleta de informações acerca dos alunos, dos professores e dos diretores de escolas em todo o Brasil. Desde 1990, a cada dois anos, o SAEB avalia, por amostragem, o desempenho dos alunos que estão terminando a $4^{\text {a }}$ e a $8^{\text {a }}$ séries do Ensino Fundamental e a $3^{\text {a }}$ série do Ensino Médio, nas disciplinas de Língua Portuguesa (foco: leitura) e Matemática (foco: resolução de problemas). O objetivo do SAEB é oferecer um diagnóstico qualitativo da educação básica brasileira, a fim de que as várias esferas de governo possam formular, reformular e monitorar suas políticas públicas voltadas para a área. Os resultados do SAEB vêm demonstrando a crítica qualidade da educação básica brasileira, em que os alunos apresentam sérias deficiências de letramento, capacidade de dominar códigos de leitura do mundo.

${ }^{13}$ Criado em 1998, o Exame Nacional do Ensino Médio consiste na avaliação do desempenho dos alunos que concluíram, ou estão concluindo, o $3^{\circ}$ ano do Ensino Médio. A prova visa avaliar as competências e as habilidades desenvolvidas pelos inscritos durante os ensinos Fundamental e Médio, imprescindíveis à vida acadêmica, ao mundo do trabalho e ao exercício da cidadania. A inscrição no ENEM é voluntária e não há limite de vezes para fazer o exame. Ao final, o candidato recebe um Boletim de Resultados, que é divulgado apenas com sua autorização expressa. A prova é composta por questões que abrangem todas as disciplinas presentes no Ensino Médio.

${ }^{14}$ Entre os educadores brasileiros existe uma discussão acerca do caráter normativo dos Parâmetros. Muitos apontam o paradoxo de serem apresentados como não obrigatórios, auxiliares, e, ao mesmo tempo, servirem como um dos critérios de avaliação qualitativa do sistema educacional brasileiro. Sobre o caráter normativo dos PGNs, cf. Corinta Maria Grisolia Geraldi, "A cartilha Caminho Suave não morreu: MEC lança sua edição revista e adaptada aos moldes neoliberais", Maria Teresa Esteban (org.), Avaliação: uma prática em busca de novos sentidos, Rio de Janeiro, DP\&A, 2001.
} 
indicadores estatísticos, não são uma especificidade do caso brasileiro, muito pelo contrário, vão ao encontro de um movimento maior, de formulação de instrumentos de avaliação internacional da educação. Por exemplo, o Programa Internacional de Avaliação de Alunos (PISA), implementado pela Organização para a Coordenação do Desenvolvimento Econômico (OCDE), avalia alunos na faixa dos 15 anos, construindo indicadores sobre a efetividade dos sistemas educacionais, dentro de uma perspectiva comparada. ${ }^{15}$

Além do planejamento e da avaliação, os PCNs se fazem presentes, também, na produção de materiais didáticos. Desde 1995, o Ministério da Educação retomou a distribuição do livro didático no Ensino Fundamental, para todas as escolas públicas brasileiras. ${ }^{16}$ No ano seguinte, pela primeira vez, ocorre o processo de avaliação pedagógica dos livros inscritos no Programa Nacional do Livro Didático (PNLD), de 1997. A partir de 1996, o MEC exclui de suas compras livros que apresentam erros conceituais, indução a erros, desatualização e preconceito ou discriminação de qualquer tipo. Posteriormente, ao invés de livros avulsos, são avaliadas somente coleções didáticas, e os critérios de exclusão são aperfeiçoados. Com o lançamento dos PCNs, passa a ser muito recorrente a presença de selos nas capas dos livros didáticos anunciando suas adequações aos Parâmetros. Logo, há um movimento de revisão dos materiais didáticos feitos pelas editoras, tanto para se adequar à nova proposta curricular, como para se adaptar aos critérios de avaliação do PNLD.

A divulgação dos Parâmetros também se faz bastante presente pela via da TV Escola, criada em 1995, cujo sinal é transmitido para todas as escolas brasileiras de porte médio. Sua grade de programação é bastante vinculada aos PCNs. Os programas apresentados são classificados de acordo com o nível de ensino (infantil, fundamental e médio) e a área de conhecimento a que se destinam. Com isto, sugerem formas de trabalhar com temas ou conceitos presentes nos Parâmetros.

Apesar de eles serem apresentados como auxiliares, a análise das políticas públicas de educação de Paulo Renato Souza demonstra todo o investimento feito pelo MEC em transformar o proposto nos PCNs em realidade, seja adotando-os como um dos critérios de avaliação do sistema de ensino

${ }^{15}$ Cf. www.mec.gov.br.

${ }^{16}$ Em 2006, a União começou a distribuir livros didáticos para as escolas públicas de Ensino Médio, iniciando com os livros de Língua Portuguesa e Matemática. Os livros didáticos de História, assim como os demais, serão distribuídos em 2007. 
brasileiro, seja incorporando-os à produção de materiais didáticos. Mesmo após todos os investimentos, os PCNs para o Ensino Médio continuam tendo poucos ecos nas escolas; resta saber o porquê. Uma das respostas encontra-se na história do Ensino Médio no Brasil.

\section{O Ensino Médio: em busca de um lugar}

Desde a década de 1990, grande parte dos documentos produzidos pelo governo federal acerca da situação da educação brasileira utiliza dados estatísticos elaborados pelo Instituto Nacional de Estudos e Pesquisas Educacionais Anísio Teixeira (INEP) e pelo Instituto Brasileiro de Geografia e Estatística (IBGE), para demonstrar que o Ensino Médio passa, desde o final dos anos 1980, por um processo de expansão significativo de matrículas. Quanto ao Ensino Fundamental, o processo teve início nos anos 1970, sendo que, na atualidade, praticamente vivenciamos a universalização de seu acesso.

A expansão das matrículas e a distância da universalização são os argumentos utilizados nos PCNs para justificar a necessidade de uma reforma do Ensino Médio. Em menos de 10 anos, de 1988 a 1997, as matrículas cresceram em mais de $90 \%$. Apesar da expansão, ao se considerar a população de 15 a 17 anos, idade adequada para freqüentar tal nível, constata-se que o índice de escolarização não ultrapassa 25\%. Bem abaixo dos países do Cone Sul, em que o índice alcança de $55 \%$ a $60 \%$.

Ao mesmo tempo em que se verifica uma explosão na demanda, constata-se uma concentração das matrículas nas redes públicas estaduais e no período noturno. Estudos do INEP, feitos em nove estados, com concluintes do Ensino Médio, demonstram que $54 \%$ são originários de famílias com renda mensal de até 6 salários mínimos. Com base nestes dados, o texto dos Parâmetros conclui que, pela primeira vez, existe uma incorporação de jovens e adultos de classes sociais que nunca participaram deste nível de ensino, tão voltado, na sua história, para a formação das elites brasileiras.

A história do ensino secundário no Brasil, não muito diferente de nossos vizinhos da América Latina, é marcada pela existência de uma dualidade entre os tipos de formação: a profissionalizante, endereçada aos trabalhadores, e a propedêutica, com vistas ao ensino superior, direcionada para as elites. Esta dualidade se faz presente desde o início da República. À época, a formação 
Apontamentos para pensar o ensino de História hoje: reformas curriculares, Ensino Médio e formação do professor

profissional era tida como uma maneira eficiente de moralizar os pobres, ensinando-lhes um ofício. ${ }^{17}$

Em 1909, 19 escolas de artes e ofícios foram criadas por todo o Brasil. Além destas escolas, aos trabalhadores era dada a opção de freqüentar o curso rural ou o curso profissional, com duração de 4 anos. Para os egressos de tais cursos, no nível ginasial, só havia opções de ensino para o mundo do trabalho: o curso normal, o curso técnico comercial e o técnico agrícola.

Um outro percurso escolar era planejado para os filhos das elites. Distantes dos trabalhos manuais, suas escolas contemplavam uma formação de cunho geral, iniciando no ensino primário, passando pelo secundário propedêutico e terminando no superior.

Esta dualidade na formação escolar obteve reforço na década de 1940. Por iniciativa de Gustavo Capanema, Ministro da Educação e Saúde de Getúlio Vargas, entre 1942 e 1946, entraram em vigência as Leis Orgânicas de Ensino. Para os alunos egressos das classes trabalhadoras, foram criados vários cursos técnicos de $2^{\circ}$ ciclo, o ensino agrícola (Decreto-lei no 9.613/46), o comercial (Decreto-lei $\mathrm{n}^{\circ} 6.141 / 43$ ), o industrial (Decreto-lei $\mathrm{n}^{\circ}$ 4.073/42) e o curso normal (Decreto-lei $\mathrm{n}^{\circ} 8.530 / 46$ ). Além destes, foram criados dois sistemas privados para a formação profissional: o Serviço Nacional de Aprendizagem Industrial (SENAI) e o Serviço Nacional de Aprendizagem Comercial (SENAC). Os diplomas de tais cursos não eram aceitos para entrar no ensino superior.

No caso das elites, mais uma vez a trajetória escolar era distinta. Através do Decreto-lei $\mathrm{n}^{\circ}$ 4.244, de 9 de abril de 1942, foram criados o científico e o clássico, dois cursos médios de $2^{\circ}$ ciclo, com duração de 3 anos. Estes eram os cursos que mantinham o caráter propedêutico, dando acesso ao ensino superior.

Em 1961, a Lei de Diretrizes e Bases da Educação (nº 4.024, de 20/12/61) integrou o ensino profissional ao sistema regular, equiparando os cursos profissionalizantes e propedêuticos, para fins de acesso ao ensino superior. Passados 10 anos, em 1971, a nova Lei de Diretrizes e Bases da Educação propôs a superação da dualidade, através da obrigatoriedade do ensino profissionalizante. Tal medida sofreu enorme resistência de setores da sociedade, que lutaram pela manutenção do caráter propedêutico deste nível de ensino. Em 1975, o

${ }^{17} \mathrm{O}$ breve histórico do ensino secundário no Brasil foi extraído de Clarice Nunes, Ensino médio, Rio de Janeiro, DP\&A, 2002. 
Parecer $\mathrm{n}^{\circ} 76$ eliminou a obrigatoriedade da profissionalização e restabeleceu a formação geral no Ensino Médio, sendo reafirmado pela Lei no 7.044/82.

A Lei de Diretrizes e Bases da Educação de 1996 estabeleceu ser o Ensino Médio a etapa final da Educação Básica. Pela primeira vez na educação brasileira, o Ensino Médio adquiriu uma função formativa em si, rompendo com as diretrizes propedêutica e profissionalizante. Neste sentido, a Lei ${ }^{\circ}$ 9.394, de 20 de dezembro de 1996, busca distanciar-se da dualidade que marca este nível de ensino desde o início do século XX.

Os PCNs para o Ensino Médio foram formulados tendo como horizonte este distanciamento da dualidade. Trata-se de um nível de ensino que, atualmente, ao menos do ponto de vista legal, possui um lugar em si, e não mais voltado para preparar para um ofício ou para ascender ao ensino superior. Como etapa final da Educação Básica, o Ensino Médio adquire o papel de finalização de uma formação que se inicia, pelo menos, 8 anos antes. No entanto, é preciso lembrar que existe uma grande diferença entre o lugar proposto pela LDB de 1996 para o Ensino Médio, reafirmado nos PCNs, e o papel que tal nível desempenha na prática. Como professor da disciplina Prática de Ensino de História, na Faculdade de Formação de Professores da UERJ, trabalhando há 4 anos com colégios públicos estaduais de Ensino Médio, situados no município de São Gonçalo, é possível perceber algumas das lacunas deste nível de ensino.

O Ensino Médio parece pouco contribuir para a formação dos alunos, muitos possuindo problemas bastante significativos de letramento ${ }^{18}$ algo que se verifica com os resultados das provas do Sistema de Avaliação da Educação Básica (SAEB). Tudo indica que, em muitas escolas, o Ensino Médio nada mais é do que um lugar de certificação, no qual é possível obter um diploma mais valorizado no mercado de trabalho do que o do Ensino Fundamental.

Atualmente, o Ensino Médio parece distante tanto da profissionalização, quanto da formação para acessar o ensino superior. No entanto, muitos de seus alunos querem tentar o vestibular. De alguma forma, a perspectiva de lugar de passagem para um outro nível ainda é bastante presente e tende a ser reforçada, pois vivemos um momento em que se adota como política pública de educação a bandeira da universidade para todos. Não é por acaso que, na década de 1990, se espalham, ao menos pelo Rio de Janeiro, os pré-vestibulares comunitários, que possuem a tarefa de preparar os alunos carentes para presta-

${ }^{18}$ Letramento é o processo de inserção na cultura escrita. 
Apontamentos para pensar o ensino de História hoje: reformas curriculares, Ensino Médio e formação do professor

rem, com mínimas chances, os concursos de acesso a diversas universidades. Não custa lembrar que o apoio financeiro a estes pré-vestibulares ganhou status de política pública durante a gestão de Paulo Renato Souza. Não deixa de ser um paradoxo, se pensarmos que tal política foi implementada justamente na gestão do ministro que propôs um lugar próprio para o Ensino Médio, para além do caráter propedêutico e profissionalizante.

\section{Olugar da História nos PCNs e além}

Nos PCNs referentes aos dois primeiros ciclos do Ensino Fundamental, ${ }^{19}$ publicados em 1997, a disciplina Estudos Sociais, marca das reformas curriculares dos anos 1970, é substituída por História e Geografia, sinalizando ao professor a necessidade de trabalhar noções introdutórias destas disciplinas com os alunos. Além desta substituição, os PCNs organizam os conteúdos de História por eixos temáticos: História local e do cotidiano (1ำ ciclo) e História das organizações populacionais ( $2^{\circ}$ ciclo) ${ }^{20}$

A opção de organizar os conteúdos por eixos temáticos também se manteve nos PCNs voltados para os ciclos finais do Ensino Fundamental, editados em 1998. Ao professor da disciplina escolar História é sugerido trabalhar com a História das relações sociais, da cultura e do trabalho, no $3^{\circ}$ ciclo, e a História das representações e das relações de poder, no $4^{\circ}$ ciclo. $^{21}$

Além de organizarem os conteúdos por eixos temáticos, os PCNs para o Ensino Fundamental traçam objetivos gerais para o ensino de História, visando que os alunos, ao longo de 8 anos, possam ampliar a compreensão de sua realidade.

Ao analisar os currículos de História produzidos no Brasil para o Ensino Fundamental na década de 1990, Circe Bittencourt conclui que, quanto aos conteúdos, a disciplina Estudos Sociais continuava a ser hegemônica entre a $1^{\mathrm{a}}$ e a $4^{\mathrm{a}}$ séries; no entanto, da $5^{\mathrm{a}}$ série em diante, a separação entre História e Geografia era um fato. A partir da $5^{\text {a }}$ série, constata ainda que grande parte dos currículos ordenava os conteúdos, utilizando a terminologia marxista dos modos de produção. Para a história do Brasil, tenderam a reparti-la pelos eixos

\footnotetext{
${ }^{19}$ Os PCNs dividem o Ensino Fundamental em quatro ciclos: $1^{\circ}$ ciclo $\left(1^{\mathrm{a}} \mathrm{e} 2^{\mathrm{a}}\right.$ séries $), 2^{\mathrm{o}}$ ciclo ( $3^{\mathrm{a}}$ e $4^{\mathrm{a}}$ séries), $3^{\mathrm{o}}$ ciclo ( $5^{\mathrm{a}}$ e $6^{\mathrm{a}}$ séries) e $4^{\mathrm{o}}$ ciclo ( $7^{\mathrm{a}}$ e $8^{\mathrm{a}}$ séries $)$.

${ }^{20}$ BRASIL, SECRETARIA DE EDUCAÇÃO FUNDAMENTAL, Parâmetros curriculares nacionais: história, geografia, Brasília, MEC/SEF, 1998.

${ }^{21}$ Idem, Parâmetros curriculares nacionais: história, Brasília, MEC/SEF, 1998.
} 
políticos (Colônia, Império e República) ou pelos ciclos econômicos (da borracha, da cana-de-açúcar, do ouro e do café). Eram minoritários os currículos que organizavam os conteúdos por temas geradores ou eixos temáticos. ${ }^{22}$ Logo, as opções feitas nos PCNs para o Ensino Fundamental trilharam o caminho do que não era hegemônico, eliminando os Estudos Sociais de todas as séries e ordenando os conteúdos por eixos temáticos.

Os PCNs para o Ensino Fundamental foram construídos, de alguma maneira, no diálogo com a produção curricular dos estados e municípios das décadas de 1980 e $1990 .{ }^{23}$ Quanto à História, é possível, inclusive, perceber inspirações em certas propostas curriculares, como no caso do currículo formulado pela Secretaria de Educação do Estado de São Paulo, na segunda metade dos anos $1980 .{ }^{24}$ Distante desta produção curricular, os PCNs para o Ensino Médio foram organizados de modo muito diferente, tendo como base a definição das competências e das habilidades que o aluno deveria desenvolver durante este nível de ensino. Esta forma de organização de currículo, como visto, foi bastante utilizada pelo MEC no início dos anos 2000.

$\mathrm{Na}$ primeira versão dos PCNs, de 1999, é feita uma argumentação acerca do sentido da área de Ciências Humanas e suas Tecnologias no Ensino Médio, baseada na retomada e na atualização da educação humanista. Esta argumentação associa os princípios estéticos, políticos e éticos - previstos nas Diretrizes Curriculares Nacionais para o Ensino Médio como fundamentais para a organização escolar e curricular - com os princípios propostos pela Comissão Internacional sobre Educação para o Século XXI, da UNESCO, fundamentados no aprender a conhecer, a fazer, a conviver e a ser. A área adquire sentido a partir da construção de uma estética da sensibilidade, "que

\footnotetext{
${ }^{22}$ Circe Bittencourt, "Capitalismo e cidadania nas atuais propostas curriculares de história", (org.), O saber escolar na sala de aula, São Paulo, Contexto, 2001, p. 11-27.

${ }^{23}$ Antes da elaboração dos PCNs, a Fundação Carlos Chagas fez uma pesquisa acerca dos currículos formulados para o Ensino Fundamental nos anos 1990, que resultou no livro Elba Siqueira de Sá Barreto (org.), Os currículos do ensino fundamental para as escolas brasileiras, Campinas, Autores Associados, São Paulo, Fundação Carlos Chagas, 1998.

${ }^{24}$ Vários estudos foram realizados acerca desta proposta curricular de São Paulo; para aumentar o conhecimento sobre suas discussões, cf. Selva Guimarães Fonseca, op. cit.; Maria do Carmo Martins, "A CENP e a criação do currículo de história: a descontinuidade de um projeto educacional", Revista Brasileira de História, Vol. 18, nº 36, São Paulo, 1998; Claudia Sapag Ricci, "Quando os discursos não se encontram: imaginário do professor de história e a reforma curricular dos anos 80 em São Paulo", Revista Brasileira de História, Vol. 18, n 36, São Paulo, 1998.
} 
Apontamentos para pensar o ensino de História hoje: reformas curriculares, Ensino Médio e formação do professor

supera a padronização e estimula a criatividade e o espírito inventivo", de uma política da igualdade, "que consagra o Estado de Direito e a democracia", e de uma ética da identidade, "desafio de uma educação voltada para a constituição de identidades responsáveis e solidárias". ${ }^{25}$

Os PCNs para o Ensino Médio compartilham da interpretação de que o mundo do século XXI está em constante e acelerada transformação, fruto da globalização. Ao longo do texto, surgem termos como sociedade do conhecimento ou sociedade tecnológica para classificar este mundo, que, supostamente, tende a fragmentar identidades. Dentro desta perspectiva de mudanças aceleradas, o aprender a conhecer ganha destaque dentre os demais princípios, pois pressupõe uma educação permanente para todos, fundada não mais na quantidade de informações, mas na capacidade de lidar com elas. Daí a opção por uma formação baseada no desenvolvimento de competências e habilidades, estruturadas em três eixos: 1. representação e comunicação; 2. investigação e compreensão; 3 . contextualização sociocultural. ${ }^{26}$

\footnotetext{
${ }^{25}$ BRASIL. SEGRETARIA DE EDUCAÇÃO MÉDIA E TEGNOLÓGICA, Parâmetros curriculares nacionais: ensino médio: ciências humanas e suas tecnologias, Brasília, MEC/SEMTEC, 1999, p. 21.

${ }^{26} \mathrm{Na}$ área de Ciências Humanas e suas Tecnologias, devem-se construir competências que permitam ao aluno: 1. "compreender os elementos cognitivos, afetivos, sociais e culturais que constituem a identidade própria e a dos outros"; 2. "compreender a sociedade, sua gênese e transformação, e os múltiplos fatores que nela intervêm, como produtos da ação humana; a si mesmo como agente social; e aos processos sociais como orientadores da dinâmica dos diferentes grupos de indivíduos"; 3. "compreender o desenvolvimento da sociedade como processo de ocupação de espaços físicos e as relações da vida humana com a paisagem, em seus desdobramentos político-sociais, culturais, econômicos e humanos"; 4. "compreender a produção e o papel histórico das instituições sociais, políticas e econômicas, associando-as às práticas dos diferentes grupos e atores sociais, aos princípios que regulam a convivência em sociedade, aos direitos e deveres da cidadania, à justiça e à distribuição dos benefícios econômicos"; 5. "traduzir os conhecimentos sobre a pessoa, a sociedade, a economia, as práticas sociais e culturais em condutas de indagação, análise, problematização e protagonismo diante de situações novas, problemas ou questões da vida pessoal, social, política, econômica e cultural"; 6. "entender os princípios das tecnologias associadas ao conhecimento do indivíduo, da sociedade e da cultura, entre as quais as de planejamento, organização, gestão e trabalho de equipe, e associá-los aos problemas que se propõem resolver"; 7. "entender o impacto das tecnologias associadas às Ciências Humanas sobre sua vida pessoal, os processos de produção, o desenvolvimento do conhecimento e a vida social"; 8. "entender a importância das tecnologias contemporâneas de comunicação e informação para planejamento, gestão, organização e fortalecimento do trabalho de equipe"; 9. "aplicar as tecnologias das Ciências Humanas e Sociais na escola, no trabalho e em outros contextos relevantes para sua vida", Ibidem, p. 26-38.
} 
A contribuição dos conhecimentos de História para a área de Ciências Humanas e suas Tecnologias, assim como de Geografia, Sociologia, Antropologia, Política e Filosofia, é tratada nos PCNs de forma bastante superficial. O texto procura responder por que ensinar História, o que ensinar e como fazê-lo. A construção dos laços de identidade e a consolidação da formação da cidadania são as principais contribuições dos conhecimentos de História, além de ensinar o aluno a ler o mundo nas entrelinhas. ${ }^{27}$

A construção da identidade é abordada no texto dos PCNs a partir de uma extensa discussão sobre as noções de tempo histórico, referenciadas na cultura. ${ }^{28} \mathrm{~A}$ discussão de tempo histórico acaba levando a uma reflexão sobre a sociedade atual, vista como um presente contínuo, "que tende a esquecer e anular a importância das relações que o presente mantém com o passado". Nesta sociedade, cabe à História, junto com o seu ensino, livrar "as novas gerações da 'amnésia social' que compromete a constituição de suas identidades individuais e coletivas". Logo, à identidade se junta a memória como mais um direito de cidadania, que implica pensar no significado de "lugares de memória", ou seja, festas, monumentos, museus, arquivos e áreas preservadas. ${ }^{29}$

No volume dedicado à área de Ciências Humanas e suas Tecnologias do PGN, de 2002, há um investimento no sentido de tentar convencer os professores das vantagens de se reformular o Ensino Médio. De forma menos superficial do que a versão de 1999, o texto explica a opção por romper a lógica de organização disciplinar dos conhecimentos tão presente no nível médio. ${ }^{30}$

${ }^{27}$ Construir identidades e formar cidadãos são papéis atribuídos à disciplina escolar História desde sua constituição. Para uma discussão sobre os significados destes conceitos nos PCNs para o Ensino Fundamental, cf. Rebeca Gontijo, "Identidade nacional e ensino de história: a diversidade como patrimônio sociocultural", Martha Abreu e Rachel Soihet (orgs.), Ensino de história: conceitos, temáticas e metodologia, Rio de Janeiro, Casa da Palavra, 2003; Marcelo de Souza Magalhães, "História e cidadania: por que ensinar história hoje?", Martha Abreu e Rachel Soihet (orgs.), Ensino de história, op cit.

${ }^{28}$ Ver crítica à questão da identidade em Eric Hobsbawm, "Não basta a história de identidade", Eric Hobsbawm, Sobre história, São Paulo, Companhia das Letras, 1998.

${ }^{29}$ A reflexão de François Hartog sobre "regime de historicidade" é muito útil para pensar o papel do ensino da História hoje, pois ajuda a compreender duas importantes funções, tanto do historiador quanto do professor, que são a desnaturalização e a historicização dos fenômenos. Cf. François Hartog, “Tempo e história: 'como escrever a história da França hoje?’”, História Social, Campinas, São Paulo, nº 3, 1996, p. 127-154.

${ }^{30}$ BRASIL, SECRETARIA DE EDUCAÇÃO MÉDIA E TEGNOLÓGICA, PCN+: ensino médio: orientações educacionais complementares aos Parâmetros Curriculares Nacionais: ciências humanas e suas tecnologias, Brasília, MEC/SEMTEC, 2002. 
Apontamentos para pensar o ensino de História hoje: reformas curriculares, Ensino Médio e formação do professor

Nos PCNs, a contribuição dos conhecimentos de História - assim como de Filosofia, Geografia e Sociologia - é valorizada na medida em que os professores busquem construir aulas baseadas em "competências e habilidades". Basta citar os títulos referentes aos conhecimentos de História para perceber o tom de diretivo desta versão complementar: Os conceitos estruturadores da História, O significado das competências específicas de História, A articulação dos conceitos estruturadores com as competências específicas da História e, por fim, Sugestões de organiæação de eixos temáticos em História. Diferente da versão de 1999, há uma preocupação em adequar a proposta curricular, com seu discurso das competências e habilidades, a uma linguagem mais familiar aos professores, dos conceitos e eixos temáticos.

O texto dos PCNs comporta uma clara dicotomia entre o velho e o novo Ensino Médio, que se quer construir. O atual Ensino Médio é visto como despreparado para dar uma formação adequada aos alunos que vivem num mundo em constante transformação, pois, ao invés de ensinar a conhecer, está bastante comprometido com um ensino portador de um caráter informativo.

Ao final de cada volume dos PGNs existe um item intitulado de Formação profissional permanente dos professores, que se divide em: A escola como espaço de formação docente e As práticas do professor em permanente formação. Este item, que não costuma estar presente em propostas curriculares, assim como não esteve na versão de 1999, é indício de que o MEC atribui à formação dos professores uma parte, talvez significativa, das dificuldades encontradas em implementar a reforma no Ensino Médio, presente nos Parâmetros Curriculares Nacionais. Logo, o problema encontra-se no professor, cuja formação ainda não está adequada a uma prática de ensino fundamentada em "competências e habilidades". ${ }^{31}$

Apontar a formação profissional do professor como um problema permite concluir o texto, retornando à análise das políticas públicas de educação. Nas Diretrizes Curriculares Nacionais para a Formação de Professores da Educação Básica, de 2001, a proposta de uma identidade profissional para o professor sai vitoriosa. Tal proposta critica claramente o modelo aplicacionista do conhecimento. De acordo com este modelo, durante um certo tempo, os alunos assistem a aulas baseadas em disciplinas e, em seguida, estagiam, aplicando

${ }^{31}$ Ibidem, p. 99-104. 
os conhecimentos aprendidos. Somente ao terminar a formação inicial é que, de fato, aprenderão o ofício na prática.

Maurice Tardif, pesquisador canadense da área de Educação, aponta que o principal problema do modelo aplicacionista é ser "idealizado segundo uma lógica disciplinar e não segundo uma lógica profissional centrada no estudo das tarefas e realidades do trabalho dos professores". ${ }^{32}$ Na perspectiva do autor, ao construir uma aula na escola, os saberes profissionais dos professores são muito mais importantes, diria até decisivos, do que os conhecimentos universitários adquiridos na formação inicial, quase sempre esquecidos. Esta pouca importância dos conhecimentos adquiridos na formação inicial pode ser colocada em dúvida através da própria resistência dos professores do Ensino Médio à proposta contida nos PCNs.

Mais do que não ser implementado por um problema de formação, a proposta vai de encontro a anos de experiências formativas acumuladas, tanto na universidade como nas escolas. Gerações de professores se formaram pensando na especificidade do ensino de suas disciplinas. No caso de História, a luta pelo fim da licenciatura curta, implantada nos anos 1970, e o desenvolvimento da pós-graduação geraram o pressuposto, até hoje válido, de que a formação do professor é indissociável da formação do pesquisador. ${ }^{33}$ Neste modelo, o professor de História adquire autonomia em sua prática docente ao saber, dentre outras coisas, como se constrói conhecimento na área. Isto permite que o professor e o pesquisador de História compartilhem uma linguagem comum, apesar da especificidade de suas práticas.

O caminho trilhado neste artigo demonstra que as críticas aos PCNs, sobretudo os do Ensino Médio, e as dificuldades surgidas na sua utilização não podem ser unicamente compreendidas a partir do problema da formação dos professores, que, inegavelmente, existem. É preciso considerar que a construção de uma proposta que se quer fundadora de um novo Ensino Médio não pode estar dissociada das práticas docentes desenvolvidas neste nível de ensino, das experiências formativas existentes até então e da história deste ensino no Brasil.

${ }^{32}$ Maurice Tardif, "Saberes profissionais dos professores e conhecimentos universitários: elementos para uma epistemologia da prática profissional dos professores e suas conseqüências em relação à formação para o magistério", Revista Brasileira de Educação, nº 13, 2000, p. 19.

${ }^{33}$ Ver, por exemplo, a proposta curricular da UFF produzida na década de 1990. 